\section{Cytochalasin B inhibits lymphocyte transformation through its effects on glucose transport}

THE effects of the fungal metabolite, cytochalasin B, on lymphocyte transformation induced by mitogenic plant lectins have been much studied ${ }^{1-7}$. Results have generally been interpreted in terms of the known effects of cytochalasin B on the microfilaments of the cellular cytoskeleton. A potential site of action which has been largely ignored lies in the inhibitory effects of cytochalasin B on metabolite transport. Cytochalasin B is a potent, competitive inhibitor of erythrocyte glucose transport ${ }^{8}$, and we have shown that it also inhibits thymocyte glucose transport, and that concanavalin A-stimulated glucose transport is more sensitive to this inhibition". Glucose transport has been shown to be rate-limiting for thymocyte glycolysis ${ }^{10}$. Also, glucose has been found to be essential for mitogen-stimulated DNA synthesis in lymphocytes ${ }^{11}$, and we show here that cytochalasin B can exert its inhibitory effect on DNA synthesis by inhibiting glucose transport.

We titrated the proliferative response of rat thymus lymphocytes to concanavalin A with various concentrations of glucose and cytochalasin B (Fig. 1). In the absence of cytochalasin B,

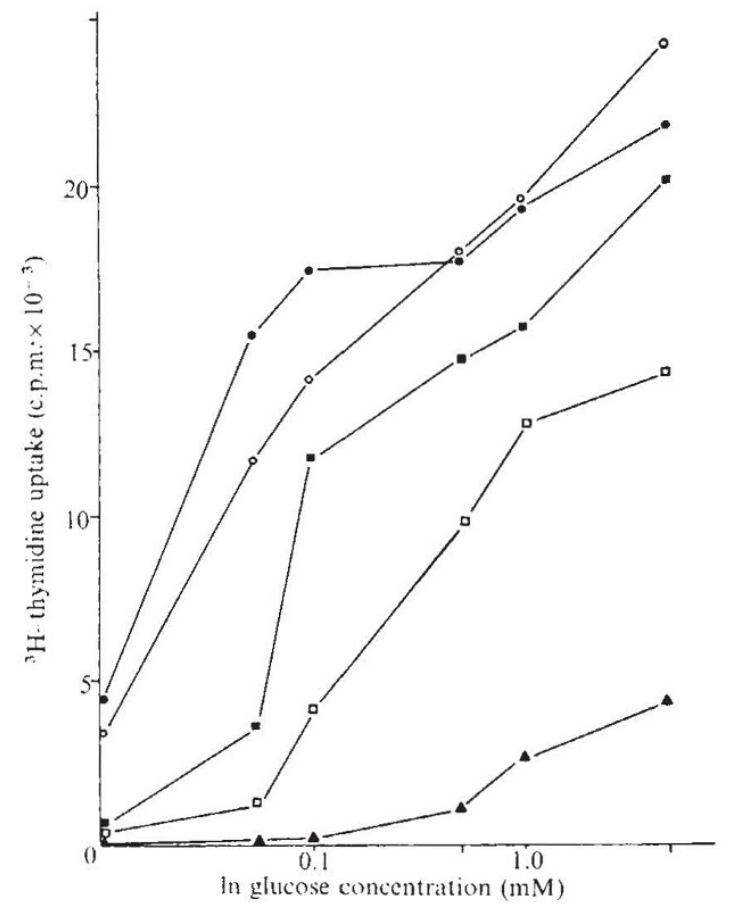

Fig. 1 The effects of glucose and cytochalasin $\mathrm{B}$ on ${ }^{3} \mathrm{H}$ thymidine incorporation into concanavalin A-stimulated rat thymocytes. Rat thymus lymphocytes from male, outbred, 7-8 week old Wistar rats were prepared in sterile phosphate buffered saline $^{3}$ and cultured in $200-\mu \mathrm{l}$ microtitre wells at a density of $5 \times$ $10^{6}$ per $\mathrm{ml}$. The medium was glucose-free Eagle's medium $+15 \%$ dialysed horse scrum (dialysed for $24 \mathrm{~h}$ against five changes of sterile phosphate buffered saline) $+50 \mu \mathrm{M} 2$-mercaptoethanol. Concanavalin A was present at a final concentration of $10 \mu \mathrm{g}$ $\mathrm{ml}^{-1}$. Cytochalasin $\mathrm{B}$ was maintained as a stock solution at $20 \mathrm{C}(20 \mathrm{mM})$ and was diluted in phosphate buffer on the day of use. The final concentration of dimethyl sulphoxide (used in the cytochalasin stock solution) in the cultures was less than $0.1 \%$. After $24 \mathrm{~h},{ }^{3} \mathrm{H}$-thymidine was added to each well, and the cells were collected on filter paper (using a Skatron automatic harvester) after a further $16 \mathrm{~h}$, and counted for radioactivity. The results are the average of three experiments, each performed in triplicate, in the which the pattern of the response was the same on each occasion. Background ${ }^{3} \mathrm{H}$-thymidine uptake was around 200 c.p.m. The graphs show the effect of glucose in the presence of concanavalin A plus $(\bullet)$, no addition; $(0), 0.1 \mu \mathrm{M}$ cyto-

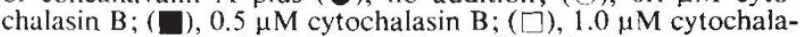
$\sin \mathrm{B} ;(\mathbf{\Delta}), 5.0 \mu \mathrm{M}$ cytochalasin $\mathrm{B}$. the effect of glucose was biphasic, while little DNA synthesis was observed in the absence of added glucose. Very low concentrations of glucose $(50 \mu \mathrm{M})$ caused a substantial stimulation of ${ }^{3} \mathrm{H}$-thymidine uptake, and a further smaller stimulation was observed as the concentration of glucose became saturating for the glucose carrier $\left(K_{m}=0.3 \mathrm{mM}\right.$, ref. 11). The effects of cytochalasin B were clearly dependent on the glucose concentration in the medium. In the absence of glucose, or at low concentrations, cytochalasin B was inhibitory at all concentrations tested. A stimulatory effect of low concentrations of cytochalasin $\mathbf{B}^{2,7}$ was only observed at supersaturating glucose concentrations. From Fig. 1 it is clear that glucose can overcome the inhibitory effects of cytochalasin B, as one would expect if the inhibition of glucose transport by cytochalasin B were competitive. Strangely, studies in lymphocytes ${ }^{13}$ have failed to observe competitive binding of glucose and cytochalasin B to high affinity plasma membrane sites. This has been observed in erythrocytes ${ }^{8}$, and the concentrations of cytochalasin B which inhibit lymphocyte glucose transport ${ }^{9}$ are close to the reported affinity of the erythrocyte glucose carrier for cytochalasin $\mathbf{B}$.

Glucose is probably required in lymphocyte proliferation for the synthesis of precursors. The de novo synthesis of purines and pyrimidines may be essential for lymphocyte proliferation ${ }^{12}$. Similarly, cytochalasin B induced inhibition of phospholipid metabolism in mitogen-treated lymphocytes may result from a lack of $\alpha$-glycerophosphate due to an inhibition of glycolysis ${ }^{3}$. It is particularly interesting to note that lymphocytes escape the inhibitory effects of cytochalasin B within a few hours of addition of the mitogen ${ }^{3, ?}$.

In conclusion, our results suggest that greater care should be taken in interpreting the effects of cytochalasin B on lymphocyte transformation, which may be primarily due to effects on metabolite transport. This caution may be applied to the many other systems in which cytochalasin B has been used, and in which glucose is an important source of energy, or precursors.
D. A. Hume
K. HANSEN
M. J. WEIDEMANN
E. FERBER

Max-Planck-Institut für Immunbiologie, 78-Freiburg-Zähringen, FRG

Received 21 November 1977; accepted 3 February 1978.

1. Hoffman, R., Ferguson, R. \& Simmons, R. L. J. Immun. 118, 1472-1479 (1977).

2. Green, W. C., Parker, C. M. \& Parker, C. W. Expl Cell Res. 103, $109-117$ (1976).

3. Resch, K., Prester, M., Ferber, E. \& Gelfand, E. W. J. Immun. 117, 1705-1710 (1976).

4. Yoshinaga, M., Yoshinaga, A. \& Waksman, B. H. Proc. natn. Acad. Sci. U.S.A. 69, 3251-3255 (1972).

5. Medrano, E. Piras, R. \& Murdoh, J. Expl Cell Res. 86, 295-300 (1974)

6. Ono, M. \& Hozumi, M. Biochem. biophys. Res. Commun. 53, 342-349 (1973).

Gery, I. \& Edinger, D. Cell Immun. 30, 147-155 (1977)

8. Lin, S. \& Spudich, J. A. J. biol. Chem. 249, 5778-5783 (1974).

9. Hume, D. A. \& Weidemann, M. J. J. cell. Physiol. (in the press). Yiophys. Acta $500,89-102$ (1977).

biophys. Acta 500, 89-102 (1977). 1120 (1976).
Kay, J. E. Biochem. Soc. Trans, 4, 1120 .

12. Hovi, T. Smyth, J. F., Allison, A. C. \& Williams, S. C. Clin. exp. Immun. 23, 395-403 (1976).

13. Parker, C. W., Greene, W. C. \& MacDonald, H. H. Expl Cell Res. 103, 99-108 (1976).

\section{Association between an $H L A$ haplotype and low responsiveness to tetanus toxoid in man}

THE major histocompatibility complex (MHC) in man, the HLA gene complex, has been assumed to code not only for histocompatibility antigens but also for immune responsiveness and control of disease susceptibility ${ }^{1}$. Although several attempts have been made to delineate the existence of $H L A$-linked immune response genes ( $I r$ genes) in man, the data are controversial ${ }^{2-6}$. We demonstrate here a striking association between a particular $H L A$ haplotype and low responsiveness to tetanus toxoid in vitro, which suggests that immune suppression genes exist in man.

Ninety-two Japanese premedical students were given a primary intramuscular immunisation with tetanus toxoid (5 L.F of the 